\title{
A Study on the Teaching System of Design Psychology
}

\author{
Shu Zhang \\ College of Art and Design \\ Wuhan University of Science and Technology \\ Wuhan, Hubei, China
}

\author{
Xinping Yuan* \\ College of Art and Design \\ Wuhan University of Science and Technology \\ Wuhan, Hubei, China \\ *Corresponding author
}

\begin{abstract}
Nowadays, the pure theoretical teaching could no longer adapt to the cultivation of practical design talents. In order to strengthen the relationship between design psychology courses and social practice and also to ensure students have a better understanding of the customer's real needs and the potential problems in the actual design, the author should try to reconstruct the curriculum system of design psychology based on the teaching content of design psychology so that students could have a better mastery of both the design psychology theories and the practical operation. In the reconstructed curriculum system, training teaching would be adopted and the author would introduce its advantage in the design psychology teaching by illustrating the following three features of this teaching method: diversity, applicability and application design so as to promote training teaching.
\end{abstract}

Keywords-design psychology; teaching system; practice teaching; training teaching; diversity

\section{INTRODUCTION}

With China's rapid development and the improvement of aesthetic level of the public, more and more consumers pay attention to psychology and psychology learning has become increasingly important. Besides, there is psychology major in many universities and colleges or there is psychological counseling course for students of each major, even including the art and design majors. In the past few years, the psychology teaching mainly focused on theoretical teaching with little or even no practical operation involved. However, in recent years, with the changes in the social demand from theoretical talents to practical talents, many higher institutions at home begin to adapt the teaching syllabus to the social development and demand and the courses are adjusted accordingly. Thus, the reconstruction of the teaching system of design psychology is inevitable and to conduct studies in this aspect is of great necessity, which is the motivation and purpose of the present research.

What's more, design psychology is an optional course for the art and design majors (visual communication design direction) and it is a discipline that explores the psychological rules of the design activities. Design psychology tries to review the development history of design activities from the perspective of users and consumers so that designers could have a deeper understanding of the real needs and aesthetics of

\footnotetext{
*Corresponding author: Xinping Yuan
}

the customers. Besides, it could also provide theoretical guidance and strong scientific basis for design practice.

\section{THE CONST RUCTION OFTHE TEACHING SYSTEM OF DESIGN PSYCHOLOGY}

For those college students born in the 1990s, they have been educated in a learning environment with plenty of information sources since they entered school and they have strong abilities to accept new things, higher autonomy and independence, so it is much necessary to construct a teaching system of design psychology fit for these students. Since the new teaching system aims to tap and motivate students' exploration ability and self-learning ability to a larger extent, the modern teaching mode which centers on students could be applied in the design psychology teaching, which is also the key research point of the present teaching system. The construction of this teaching system mainly covers the following four aspects.

\section{A. Changes in the Psychology Teaching Objective}

In the early days, the psychology courses were all theoretical instruction while in the new teaching system, one third of the study hours has been assigned for practical operation, which shows the fundamental change in the teaching objective. As for the practical operation, it aims to promote students' classroom participation, active thinking and self-learning abilities based on the course content of design psychology and it also helps students to fulfill the training objective. With the change in the teaching objective, it attaches great importance to research methodology of design psychology, customers' emotional state and the actual operation and innovation abilities, thus, students could have a deeper understanding of marketing and advertisement psychology in their art designs.

\section{B. The Implementation of the Psychology Teaching Content}

In the actual instruction of design psychology, teachers could design some practical tasks based on the theoretical knowledge so that theoretical guidance is delivered in the process of practical operation. Let's take the classification of consumers for example, students could go to the physical stores or hypermarkets to observe the actual activities of the consumers and then they could make their own judgment, e.g. 
who are the seed customers? who are the prospective customers? etc. Besides, teachers could also arouse students' enthusiasm and promote their motivation by introducing certain design projects of some companies and students are allowed to audit when the teachers negotiate with the company head on the design plan in the late stage. In this way, students could have a better understanding of the market demand.

\section{The Innovation of the Psychology Teaching Method}

With the changes in the teaching content, the teaching methods should be innovated accordingly, especially for the theoretical instruction. It is known that many psychology theories are boring in themselves and pure blackboard writing instruction only makes the situation even worse. Thus, modern teaching methods could be employed in the actual teaching such as multimedia courseware, pictures and videos, which could not only make better use of teaching time but also broaden students' international vision and finally enhance teaching effects. Besides, in the process of theoretical instruction, teachers could introduce cases or arrange group discussion or even role-play on some special occasions. All in all, through the innovation of teaching methods, it aims to create a relaxed and pleasant learning environment for students so that they could be more active in the classroom learning and no longer become passive learners.

\section{The Reform of the Psychology Assessment}

The reform of the psychology assessment is both a dispensable and important part of the whole psychology teaching. In the early days, the as sessment was in the form of paper-based examination which could only assess students' immediate memory capacity but it is incompetent in assessing students' deep understanding on knowledge points and their knowledge application abilities. Thus, the reformed as sessment should be diversified and apart from paper-based examination, there could be other assessment methods such as classroom discussion, market investigation, role-play or some comprehensive test items such as case analys is with open answers. All in all, the assessment aims to check students' problem analysis abilities, thinking abilities and problem solving abilities.

\section{TRAINING TEACHING CASES}

\section{A. The Diversity of Design Psychology Teaching Method}

In the early days, the design psychology teaching was featured with cramming method of theoretical instruction. This boring teaching even lasted for a long time and was unpopular among the students. In fact, through this teaching method, students only established immediate memory on what they have learned by cramming before the examination, but when the examination is over, are there students who can really understand the theories or even skillfully apply them into practice? The answer is really pessimistic. Thus, in recent year, I have been exploring how to enhance the teaching effects of design psychology in my teaching process. Many researchers at home have proposed case-based teaching. In the early stage, case-based teaching received many good feedbacks as it motivated students' active participation and the teaching effect was very good, however, with the market expansion and the city's rapid development, students are required to strengthen their professional theories learning in the practice with the hope that it could enhance students' social practice abilities. Thus, the teaching method of combining theoretical instruction with case-based teaching could no longer meet the requirements of the school and society.

Under this comprehensive circumstance, a new teaching method comes into being. "Training teaching" is a teaching module newly introduced in the design psychology teaching and it is more practical. Thus, the present teaching process of design psychology is as follows: theoretical instruction plus pioneering case-based teaching plus training teaching, among which training teaching is a kind of teaching module composed of "investigation plus redesign" which has closer relationship with society. The newly teaching mode would make the teaching method of design psychology more diversified.

\section{B. The Application Significance of Training Teaching in the Actual Teaching}

In the goods selling, apart from the goods quality and brand guarantee, the visual design of the goods has become another key factor that could promote goods sales and the sales performance. The large quantities of goods displayed in the hypermarkets have not only enriched the customers' visual sense to a large extent but also improved consumers' aesthetic sense. The plain designs could no longer arouse consumers' purchase desire, thus, designers need to have a better understanding of consumers' buying purpose before they design. This means that designers should be equipped with some psychology knowledge. The design innovation is important to both enterprises and consumers but cased-based teaching can't meet the require ments of the society in actuality and practicality while training teaching is a kind of teaching mode that could provide correct guidance in the actual teaching. Training teaching is a concrete teaching activity designed to achieve a specific teaching goal of the practical operation section and in the training teaching, all the project work is divided among the students including investigation, redesign, report and evaluation. Through these practical activities, the interactivity among students becomes frequent and it could greatly stimulate students' self-learning interest. In terms of teaching effect, training teaching delivers richer resources and goals than case-based teaching and it cultivates students' abilities in problem discovery, analyzing problems, problem-solving and making summaries, thus making a good combination of professional abilities and social require ments.

\section{The Application Design of Training Teaching in the Actual Teaching}

In the training teaching, students are divided into several training groups and each group could select a topic freely or the teacher assign a topic for each group. Then each group need to finish the task according to the requirements. Training teaching aims to improve students' cooperation in a group as well as their professional abilities of comprehensive practice and the whole teaching process can be divided into the following five stages. 
- The stage of work division and topic selection: the whole class shall be divided into several groups with three to four me mbers for each group or four me mbers at most for each group. Since psychological factors play an important role in the design, students should carry out project design of the actual brand under the teacher's guidance or regulation. Besides, virtual brand in this stage is free from actual marketing or post-evaluation, so it should not be recommended to the students and teachers in this stage implement strict standard on the topic selection.

- The stage of market research of the project: after the topic is determined, the main character should be s witched from teacher to student and in order to have a full understanding of the consumer psychology of the consumers and the design feedback of the company design, work division with specific objective should be conducted among students in this stage and different market research methods would be employed to conduct target investigations. For example, separate interview, market observation, questionnaire, sample comparison, etc could be employed to investigate problems in different aspects such as products, product image, package design, poster design, dynamic creative advertising design, the actual consumer psychology of the consumers, etc. and then the investigation results will be gathered.

- The stage of project redesign: in this stage, the main character is still the student. Students should conduct multi-dimensional discussion based on each group's investigation results and the consumers' valid opinions while the teacher could provide guidance and assistance in the process of the discussion. Then students begin to redesign products or relevant information of the company based on the discussion results. In this stage, students' design objective and the market de mand should be highlighted.

- The stage of project show presentation: after the redesign, the electronic version of the finished work will be presented by one member of each group for inter-group discussion with the use of multimedia tools. In order to display students' professional abilities, the finished work could also be presented in the form of pictures, entities, television animation, etc. according to the market effects. After the presentation, other groups could play the role of the head of the project company and ask some questions concerning design objective, the implementation details, design method, etc. so that students could consider redesign from different aspects while the teacher could provide counseling or evaluation. In this stage, students learn to consider the actual problems in design from the perspective of project company through this role-play activity and this could improve their professional skills.

- The stage of the project follow-up evaluation: in this stage, students need to make summaries. At first, the group members make self-evaluation and then mutual evaluation between other groups is conducted with a specific mark given. Finally, the teacher makes a summary comment on the feasibility, limitation and problems to be corrected in the practical operation with another mark given. By comparing the mark from the students and that from the teacher, students need to summarize their common opinions and differences. Only through self-criticis $m$ and mutual-criticis $m$ can common improvement be achieved in the whole class.

\section{CONCLUSION}

Training teaching in the design psychology is mainly about students' practical operation organized according to the specificity and professional features of design courses and it focuses on students' innovation abilities and problem-solving abilities. This teaching method could motivate students' selflearning and enhance classroom teaching effects to a large extent, thus, it has better student participation than case-based teaching. Being featured with confirmation of actual social projects, students' autonomy and interactivity and studentcentered activities, the design psychology instruction could not only cultivate teamwork spirit among students but also create a joyful learning environment. The biggest difference between training teaching and the traditional boring theoretical instruction is that students are more concentrated and with stronger thinking abilities while the most important point is that students have better understanding of the theories and stronger social investigation abilities. From the perspective of the teacher, there is not only better classroom discipline but also better teaching effects. What's more, those evaluations and communications in which students communicate creative ideas also provide valuable learning opportunities for the teachers. It is hoped that this teaching method of combining diversified theoretical instruction with actual teaching practice could help achieve the goal of practical design talents cultivation. Though there exists some control problems in the teaching system, researches on the teaching system of design psychology could be improved with the accumulation of teaching experience and the control of actual cases. It is also hoped that a valuable teaching system which combines theory and practice and is designed for design majors could be constructed through constant improvement and further studies by relevant researchers.

\section{ACKNOWLEDGMENT}

2015 Teaching Reform Project of Hubei Province "Research and Practice on the curriculum system of visual communication design based on Chinese traditional culture". (ite m nu mber 2015231)

\section{REFERENCES}

[1] He Linlin. Discussion on the Reform of Diversified Teaching Mode of Advertising and Consumer Psychology. Frontier. No.22, 2012

[2] Wang Chunyue. Research on the Design and Teaching Process of the Experiment Teaching Content of Advertising Psychology. Modern Enterprise Culture. No. 32, 2008

[3] Che Hongsheng. Thinking on Undergraduate Curriculum for Psychology Majors. Higher Education of Sciences. No. 6, 2004 
[4] Zheng Yan. The Construction and Practice of the Experiment Course System of Consumer and Advertising Psychology. Education for Chinese After-school. 2012(12)

[5] Liang Jianian. Psychology of Design Art. Wuhan University Press. 2011.1

[6] Zheng Jinzhou. Guidebook of Case-based Teaching. Shanghai: East China Normal University Press. 2000.6

[7] Wang Chunyue. Discussion on the Case-based Teaching in Advertising Psychology. Science Education Forum. 2009(2) 